\title{
La Corte Europea de Derechos Humanos y la protección de la autonomía de las comunidades religiosas: análisis del caso Sindicatul Pãstorul cel Bun con Rumania
}

\section{The European Court of Human Rights and the protection of autonomy of religious communities: an analysis of the Sindicatul Pãstorul cel Bun v. Romania case}

\section{Stéphanie Wattier}

Universidad Católica de Lovaina, Bélgica

Estudiante de doctorado en el Centre de recherche sur l'Etat et la Constitution y en la Chaire de droit des religions de la Universidad Católica de Lovaina. Actualmente se desempeña como investigadora del Fonds national de la recherche scientifique (aspirante F.R.S.- FNRS) en Bélgica. Ha escrito numerosos artículos acerca de las relaciones entre la Iglesia y el Estado en Europa.

stephanie.wattier@uclouvain.be

\section{RESUMEN}

El presente artículo analiza la sentencia dictada por la Gran Sala de la Corte Europea de Derechos Humanos, en el caso Sindicatul Pãstorul cel Bun con Rumania de 9 de julio de 2013. La autora examina el razonamiento de la Corte Europea y describe la forma en que se ha concebido la relación entre la libertad religiosa y la libertad de asociación en la jurisprudencia del Tribunal de Estrasburgo. A partir de este análisis, concluye que actualmente no existe un modelo europeo de relaciones entre el Estado y las confesiones religiosas, lo que ha llevado a la Corte Europea a aplicar con mayor laxitud el margen de apreciación nacional.

Palabras clave: Corte Europea de Derechos Humanos - libertad religiosa - libertad sindical - margen de apreciación nacional.

\begin{abstract}
This article analyses the Grand Chamber of the European Court of Human Rights judgment in the case Sindicatul Pãstorul cel Bun v. Romania of 9 July 2013. The author analyses the reasoning of the European Court and describes the relationship between religious freedom and freedom of association in the jurisprudence of the Court of Strasbourg. Later on, she concludes that currently there is not a European model for relationships between the State and multiples Churches, which has led the Court to freely apply the national margin of appreciation.
\end{abstract}

Key words: European Court of Human Rights religious freedom - trade union freedom - national margin of appreciation. 


\section{Introducción}

El 9 de julio de 2013, la Gran Sala de la Corte Europea de Derechos Humanos (CEDH o Corte Europea), se pronunció sobre un conflicto de derechos fundamentales ${ }^{1}$ entre la libertad religiosa y la libertad sindical. En este caso, un grupo de sacerdotes miembros de la Iglesia Ortodoxa Rumana, reunidos en la asociación "Sindicatul Pãstorul cel Bun", creada en abril de 2008, buscaba que se les reconociera su calidad de sindicato y que se les inscribiera como tal en el registro nacional. Sin embargo, esta solicitud les fue denegada por el Tribunal del Condado de Dolj², al estimar que se debía respetar el derecho de las confesiones religiosas a organizarse de conformidad con sus propias tradiciones y que, en este caso, el estatuto de la Iglesia prohibía a los sacerdotes fundar asociaciones, fundaciones y organizaciones de cualquier tipo. En este sentido, el rechazo se fundaba en la necesidad de proteger la religión cristiana, sus dogmas y sus formas canónicas de decisión, y sobre el hecho de que si el sindicato fuera creado, la jerarquía de la Iglesia estaría obligada a colaborar con un organismo extranjero a sus reglas canónicas y su tradición ${ }^{3}$.

En contra de esta resolución, el sindicato interpuso una demanda ante la CEDH el 30 de diciembre de 2008, alegando que se había vulnerado su derecho a la libertad de asociación consagrado en el artículo 11 del Convenio para la Protección de los Derechos Humanos y Libertades Fundamentales (Convenio Europeo).

El presente artículo tiene por objeto analizar el razonamiento que desarrolla la CEDH ante el conflicto de derechos fundamentales entre la libertad religiosa y la libertad sindical, con el objeto de demostrar que la resolución de la $\mathrm{CEDH}$ en el caso Sindicatul Pãstorul cel Bun con Rumania, es una confirmación de la ausencia de un modelo europeo de relaciones entre el Estado y las comunidades religiosas, lo que trae consigo una amplia aplicación del margen de apreciación nacional para que los Estados protejan la autonomía de las comunidades religiosas.

\section{Libertad religiosa y de asociación: articulación y conflicto}

Cuando se trata de la libertad religiosa en su acepción colectiva ${ }^{4}$, la CEDH analiza el artículo 9 (libertad religiosa), en conjunto con el artículo 11 del Convenio Europeo, que enuncia el principio de la libertad de reunión y de asociación. En este sentido, la CEDH ha señalado que la libertad religiosa supone el derecho para los fieles de manifestar su religión individualmente, pero también colectivamente, lo que implica que los fieles pueden asociarse de manera libre. Según la CEDH, la autonomía de las comunidades religiosas es indispensable al pluralismo de una sociedad democrática y por ello, se sitúa en el centro de la protección conferida por el artículo 9 del Convenio Europeo ${ }^{5}$.

Sobre estos conflictos: DUCOULOMBIER, Peggy. Les conflits de droits fondamentaux devant la Cour européenne des droits de l'homme. París : Bruylant, L.G.D.J., 2011.

CEDH. Caso Sindicatul Pãstorul cel Bun v. Rumania. Sentencia de 31 de enero de 2012. Demanda No. 2330/09, párr.17.

Ibídem, párr.19.

Ver : SCHOUPPE, Jean-Pierre. "La dimension collective et institutionnelle de la liberté religieuse à la lumière de quelques arrêts récents de la Cour européenne des droits de l'homme". Revue trimestrielle des droits de l'homme, 2005, pp. 611-633 ; COUSSIRAT-COUSTERE, Vincent. "Manifester sa religion vu de Strasbourg. La jurisprudence de la Cour européenne des droits de l'homme". En: DUARTE, B. Manifester sa religion : droits et limites. París : L'Harmattan, 2011, pp. 11-64.

CEDH. Caso Hassan and Tchaouch v. Bulgaria. Sentencia de 26 de octubre de 2000. Demanda No. 30985/96, párr.26; caso Eglise métropolitaine de Bessarabie and others v. Moldova. Sentencia de 13 de diciembre de 2001. Demanda No. 45701/99, párr.118. 
Pese a que la $\mathrm{CEDH}$ ha tratado de manera conjunta ambos derechos, la libertad religiosa y la libertad de asociación también pueden encontrarse en conflicto, particularmente cuando la libertad de asociación se refiere a la libertad sindical, como ocurrió en el caso Sindicatul Pãstorul cel Bun con Rumania. Este tipo de conflicto es particularmente complejo, pues por una parte los Estados deben garantizar la libertad sindical, pero también deben proteger el derecho a la autonomía de las comunidades religiosas, en cuyos estatutos puede encontrarse la prohibición de formar sindicatos ${ }^{6}$. En este sentido, el caso Sindicatul Pãstorul cel Bun con Rumania es muy particular, pues por primera vez la CEDH debía juzgar un conflicto desde una perspectiva colectiva, ya que enfrenta a un sindicato (unión de varios miembros del clero) con la Iglesia y el Estado ${ }^{7}$.

\section{La deliberación de la Tercera Sala de la CEDH}

Ante la CEDH, el demandante -la asociación sindical Sindicatul Pãstorul cel Bun- invocó que el rechazo del Estado Rumano de registrarla como sindicato constituía una violación del artículo 11 del Convenio Europeo. Este artículo protege, entre otras cosas, la libertad sindical, enunciado en su párrafo 1 de la siguiente forma: "toda persona tiene derecho a la libertad de reunión pacífica y a la libertad de asociación, incluido el derecho a fundar, con otras, sindicatos y de afiliarse a los mismos para la defensa de sus intereses". Por su parte, el Estado Rumano alegó que efectivamente existía una injerencia en el derecho a la libertad sindical, pero que ésta estaba prevista por ley, perseguía una finalidad legítima y era necesaria en una sociedad democrática.

En este sentido, la tercera sala de la CEDH debía verificar si los miembros del clero podían crear un sindicato en base al artículo 11 del CEDH y, sobre estas consideraciones, determinar si había existido una violación de este derecho. El 31 de enero de 2012, la tercera sala de la CEDH se pronunció sobre la demanda interpuesta por la asociación Sindicatul Pãstorul cel Bun.

Sobre el primer punto, la tercera sala de la CEDH constató que los sacerdotes de la Iglesia Ortodoxa trabajaban en virtud de un contrato de trabajo, lo que tenía como consecuencia que el derecho civil debía ser aplicado conforme a esa relación de trabajo ${ }^{8}$. En este sentido, les era aplicable el artículo 11 del Convenio Europeo.

Por tanto, la CEDH debía determinar si el rechazo a la inscripción era una "restricción justificada", a la libertad sindical conforme al párrafo 2 del artículo 11 del Convenio ${ }^{9}$. La CEDH constató que el Tribunal Departamental de Rumania había fundamentado dicho rechazo, por una parte,

6 HERVIEU, Nicolás. "Conflit entre le droit de fonder un syndicat et le principe d'autonomie des communautés religieuses". Lettre "Actualités Droits-Libertés" du CREDOF, 3 de febrero de 2012.

Anteriormente la CEDH había juzgado conflictos interindividuales entre un clérigo y su Iglesia, como ocurrió en los casos Reuter, Baudler y Muller. Estos casos trataban sobre ministros de culto que habían sido destituidos por sus superiores jerárquicos, por lo que invocaban ante la CEDH la vulneración de sus derechos laborales. En los tres casos, la CEDH rechazó los requerimientos y confirmó la autonomía de las confesiones religiosas sobre las resoluciones que afectan a los ministros del culto, ver: CEDH. Caso Reuter v. Germany. Sentencia de 6 de diciembre de 2011. Demanda No. 39775/04; caso Baudler v. Germany. Sentencia de 6 de diciembre de 2011. Demanda No. 38254/04; caso Muller v. Germany. Sentencia de 6 de Diciembre de 2011. Demanda No.12986/04. Un análisis de estas decisiones en: WATTIER, Stéphanie. "L'article 6 de la Convention européenne des droits de I'homme : inapplicable aux révocations de ministres des cultes ?". Revue de jurisprudence Liège, Mons et Bruxelles, 2012, pp. 728-743.

8 CEDH. Caso Sindicatul Pãstorul cel Bun v. Rumania, op.cit, párr.64.

9 El párrafo 2 del artículo 11 del Convenio enuncia que "el ejercicio de estos derechos no podrá ser objeto de otras restricciones que aquellas que, previstas por la ley, constituyan medidas necesarias, en una sociedad democrática, para la seguridad nacional, la seguridad pública, la defensa del orden y la prevención del delito, la protección de la salud o de la moral, o la protección de los derechos y libertades ajenos. El presente artículo no prohíbe que se impongan restricciones legítimas al ejercicio de estos derechos por los miembros de las fuerzas armadas, de la policía o de la Administración del Estado". 
sobre las Leyes Rumanas No. 54/2003 (Ley sobre Sindicatos) y No. 489/2006 (Ley sobre Libertad Religiosa), que según la jurisprudencia rumana, prohíben la creación de sindicatos por los cleros y por otra parte, en la necesidad de proteger la religión cristiana, sus dogmas y sus formas canónicas de decisión ${ }^{10}$.

En este sentido, la tercera sala de la $\mathrm{CEDH}$, señaló que la restricción podía ser considerada como "prevista por la ley" y perseguía un objetivo legítimo, ya que estimó que la "protección del orden público" comprendía la protección de la libertad religiosa y la autonomía de las comunidades religiosas ${ }^{11}$. Sin embargo, la CEDH también indicó que los motivos esgrimidos para rechazar la inscripción del sindicato solo fueron de naturaleza religiosa y que por consiguiente, tales motivos no podían ser aceptados como "razones legítimas en una sociedad democrática", en atención al otro derecho que se buscaba proteger (libertad sindical) ${ }^{12}$. En este sentido, la Corte constató que la denegación había sido desproporcionada en relación a la finalidad perseguida y por tanto, era innecesaria en una sociedad democrática ${ }^{13}$.

En conclusión, la tercera sala de la Corte de Estrasburgo indicó que el Estado Rumano había violado el artículo 11 del Convenio Europeo.

\section{La decisión de la Gran Sala de la CEDH}

La sentencia del 9 de julio de 2013 dictada por la Gran Sala de la CEDH reforma el juicio adoptado el 31 de enero de 2012 por la tercera sala de la Corte Europea ${ }^{14}$.

La Gran Sala de la CEDH debía decidir, al igual que la tercera sala, si el artículo 11 del Convenio Europeo podía ser aplicado a los miembros del clero. Para responder a esta pregunta, la CEDH utilizó las recomendaciones de la Organización Internacional del Trabajo (OIT) y más precisamente, la recomendación No. 198 relativa a la relación de trabajo ${ }^{15}$. Esta recomendación precisa que "la existencia de una relación de trabajo debería determinarse principalmente de acuerdo con los hechos relativos a la ejecución del trabajo y la remuneración del trabajador, sin perjuicio de la manera en que se caracterice la relación en cualquier arreglo contrario, ya sea de carácter contractual o de otra naturaleza, convenido por las partes"16. Asimismo, la Gran Sala también recoge lo dispuesto en Convenio No. 87 de la OIT relativo a la libertad sindical, que enuncia en su artículo 2 que "los trabajadores y los empleadores, sin ninguna distinción y sin autorización previa, tienen el derecho de constituir organizaciones de su elección".

Sobre la base de estas consideraciones, la Gran Sala de la Corte constata que los miembros del clero mantienen en su profesión una relación jerárquica con el obispo muy similar a la relación de trabajo, pues ejecutan tareas (como ritos del culto y educación religiosa a los niños) y tienen un salario. Por esas razones, la Gran Sala de la CEDH confirma lo que había indicado la tercera

\footnotetext{
10 CEDH. Caso Sindicatul Pãstorul cel Bun v. Rumania, op.cit, párr.67.

11 Ibídem, párr.68.

12 Ibídem, párrs.73-76.

13 Ibídem, párr.87.

14 En conformidad al artículo 43 del Convenio Europeo, la Gran Sala de la CEDH puede conocer de un caso cuando el asunto plantea una cuestión grave relativa a la interpretación o a la aplicación del Convenio o de sus Protocolos o una cuestión grave de carácter general. En el caso Sindicatul Pãstorul cel Bun, el colegio de la Gran Sala aceptó la remisión del asunto el 9 de julio de 2012. La remisión fue solicitada por el Gobierno rumano el 27 de abril de 2012.

15 CEDH. Gran Sala. Caso Sindicatul Pãstorul cel Bun con Rumania. Sentencia de 9 de julio de 2013. Demanda No. 2330/09, párr.57.

16 OIT. Recomendación sobre la relación de trabajo No.198, 2006, párr.9.
} 
sala e indica que el artículo 11 del Convenio Europeo puede ser aplicado a los clérigos ${ }^{17}$.

Sin embargo, ante la deliberación acerca de si la restricción a la libertad sindical era legítima en conformidad al Convenio Europeo, el razonamiento varía. En primer lugar, la Gran Sala constata que no existe ningún principio en la Constitución Rumana o en las leyes, que prohíba expresamente la creación de sindicatos por los clérigos, pero señala que esta prohibición se encuentra en los Estatutos de la Iglesia. En concepto de la CEDH, las disposiciones de estos estatutos reúnen las condiciones de "legalidad"18 exigidas por el párrafo 2 del artículo 11 del Convenio Europeo. En este sentido, la restricción podía ser considerada como "prevista por la ley"19.

Además, según la Gran Sala, prohibir la creación de sindicatos a los clérigos constituye una restricción en la libertad sindical que persigue un objetivo legítimo en virtud del artículo 11.2 del Convenio Europeo, que es la protección de los derechos de los demás y más precisamente, los derechos de la Iglesia Ortodoxa ${ }^{20}$.

En cuanto al análisis de la "necesidad en una sociedad democrática", la Gran Sala de la CEDH precisa que el conflicto de derechos entre la libertad religiosa y la libertad sindical, debía ser resuelto por el Estado Rumano, pues cuando se trata de las relaciones entre el Estado y las confesiones religiosas, no existe ningún modelo que deba ser aplicado por todos los Estados:

Finalmente, el Tribunal toma nota de la gran variedad de modelos constitucionales existentes en Europa que regulan las relaciones entre el Estado y las confesiones religiosas. Teniendo en cuenta la falta de un consenso europeo en la materia [...], el Tribunal considera que el Estado goza de un amplio margen de apreciación en esta materia, que incluye el derecho a decidir si reconoce o no a un sindicato en el seno de una comunidad religiosa cuya actividad pueda suponer un peligro para la autonomía de esta ${ }^{21}$.

En este sentido, según la Gran Sala, el rechazo de registrar la asociación como sindicato por parte del Estado Rumano, solo consiste en una aplicación de su margen de apreciación para proteger el principio de la autonomía de las comunidades religiosas. De esta forma, la Gran Sala concluye que el rechazo de la inscripción del sindicato no sobrepasó el margen de apreciación de las autoridades naciones en la materia y por tanto la medida no fue desproporcionada, no existiendo una violación al Convenio Europeo ${ }^{22}$.

\section{Ausencia de un modelo de relaciones entre el Estado y las confesiones religiosas en Europa y margen de apreciación nacional}

La sentencia de la Gran Sala de la Corte Europea de Derechos Humanos de 9 de julio 2013, confirma la ausencia de un modelo europeo de relaciones entre el Estado y las confesiones religiosas. En efecto, en el Consejo de Europa se pueden identificar tres tipos de relaciones entre el Estado y las organizaciones religiosas.

Varios países - como por ejemplo Francia-, tienen un sistema de "separación total" entre el Es-

CEDH. Gran Sala. Caso Sindicatul Pãstorul cel Bun v. Rumania, op.cit., párrs.140-149.

La CEDH interpreta el concepto de "legalidad" de manera muy laxa. La primera decisión de la Corte en este sentido fue: CEDH. Caso Sunday Times. Sentencia de 26 de abril de 1979. Demanda No. 6538/74, párrs.46-53.

19 CEDH. Gran Sala. Caso Sindicatul Pãstorul cel Bun v. Rumania, op.cit., párrs.151-157.

Ibídem, párr.158.

Ibídem, párr.171.

Ibídem, párrs.172-173. 
Stéphanie Wattier / La Corte Europea de Derechos Humanos y la protección de la autonomía de las comunidades religiosas: análisis..

tado y las comunidades religiosas, lo que significa que no existe ningún vínculo entre el Estado y la Iglesia. En este sentido, el Estado no financia a las comunidades religiosas en estos países.

Por otro lado, también hay países denominados "Estados confesionales" (como Inglaterra, Dinamarca, Grecia o Islandia). En estos países, el Estado se adhiere a una religión en particular que recibe el nombre de "Iglesia Estatal". Por ejemplo, en Inglaterra la jefa de la Iglesia Estatal y la jefa del Estado coinciden en la persona de la Reina.

Finalmente, muchos países Europeos tienen un sistema híbrido de "cultos reconocidos" o "cultos recordados". En estos países -como por ejemplo- Alemania, Bélgica, España e Italia, las religiones y los cultos reconocidos por el Estado, tienen un estatuto más ventajoso que los demás (financiación pública a las escuelas confesionales, de los ministros del culto, privilegios fiscales, etc.).

En este sentido, frente a estas relaciones muy variadas, a la CEDH le parece imposible establecer un modelo obligatorio que deberían seguir todos los Estados y todas las comunidades religiosas para regular sus relaciones y por ello la Corte Europea deja un margen de apreciación nacional ${ }^{23}$ muy amplio a los Estados miembros del Consejo de Europa, para resolver los conflictos que impliquen deliberar acerca de la libertad religiosa. Así por ejemplo, en la famosa sentencia del caso Leyla Sahin con Turquía ${ }^{24}$, la Gran Sala de la Corte confirmó la decisión del Tribunal Constitucional, que autorizaba la prohibición del velo islámico en las universidades, utilizando la doctrina del margen de apreciación para confirmar que esta reglamentación era necesaria ${ }^{25}$.

Sin embargo, la aplicación del margen de apreciación nacional por la jurisprudencia del Tribunal de Estrasburgo no siempre es tan amplia. En efecto, la intensidad varía dependiendo del derecho o libertad de que se trate y la CEDH modula su aplicación según varios factores, como el fin perseguido por la injerencia y verifica previamente la existencia de un modelo único en Europa en la materia. En este sentido, se nota que la $\mathrm{CEDH}$ "ha reducido al mínimo el margen de apreciación estatal para interferir en el ámbito de los artículos 10 (libertad de expresión) y 11 (libertad de reunión y asociación) en virtud de su condición de elementos esenciales para garantizar el pluralismo en el seno de una sociedad democrática, por el contrario, en lo tocante

Como lo señala DíAZ, el margen de apreciación nacional "es una doctrina ampliamente utilizada por varios tribunales internacionales, especialmente el Tribunal Europeo de Derechos Humanos (TEDH, en adelante), que se traduce en una suerte de deferencia del tribunal correspondiente hacia las autoridades nacionales para que sean éstas las que decidan sobre una determinada cuestión. La aplicación de esta doctrina al ámbito de los derechos humanos ha supuesto la concesión de cierto margen de actuación a las autoridades nacionales, que serían las encargadas de resolver determinadas vulneraciones de derechos humanos, en aquellos casos en los que el tribunal internacional correspondiente considera que los órganos internos están mejor posicionados e informados que el propio órgano internacional para resolver la cuestión litigiosa" (DÍAZ, María. "Margen de apreciación". En: Diccionario Iberoamericano de Derechos Humanos y Fundamentales. España: Universidad de Alcalá, 2011). Para mayor información del concepto de margen de apreciación nacional, ver también: ACOSTA, Paola y NÚÑ̃EZ, Manuel. El margen de apreciación en el sistema interamericano de derechos humanos: proyecciones regionales y nacionales. México: Instituto de Investigaciones Jurídicas de la UNAM, 2012 y; GARCíA, Javier. El margen de apreciación nacional en la interpretación del Convenio Europeo de Derechos Humanos. Madrid: Editorial Civitas, 2010.

CEDH. Gran Sala. Caso Leyla Sahin v. Turquía. Sentencia de 10 de noviembre de 2005. Demanda No.44774/98.

Según la CEDH "cuando están en juego cuestiones relativas a la relación entre el Estado y las confesiones religiosas, respecto de las cuales las opiniones en una sociedad democrática pueden diferir ampliamente, debe concederse una importancia especial al papel del órgano nacional [...] No se puede discernir en Europa una concepción uniforme sobre el significado de la religión en la sociedad y el significado o impacto de la expresión pública de una creencia diferirá según el momento y el contexto. Consecuentemente, las normas en esta esfera variarán de un país a otro según las tradiciones nacionales, así como las exigencias impuestas por la necesidad de proteger los derechos de los demás y mantener el orden público. Por tanto, la elección de la extensión y la forma de tales regulaciones debe dejarse inevitablemente hasta cierto punto al Estado interesado, puesto que dependerá del contexto doméstico". Ibídem, párr.109. 
a la libertad de conciencia y religiosa aquél ha enfatizado la incidencia de ciertos factores que operan en la dirección contraria, ampliando enormemente ese margen discrecional en la actuación estatal"26.

En efecto, la libertad de expresión y la libertad de reunión y asociación implican un margen de apreciación muy limitado, pues existe efectivamente un modelo común en Europa sobre la materia, pero respecto de la protección de la autonomía de las comunidades religiosas se ha ampliado la aplicación del margen de apreciación nacional. En este sentido, el caso Sindicatul Pãstorul cel Bun con Rumania, muestra una vez más que no existe una concepción común de la relación entre las comunidades religiosas y el Estado en Europa, lo que genera en la práctica una victoria de la libertad religiosa por sobre otros derechos y libertades.

\section{Conclusión}

La sentencia del caso Sindicatul Pãstorul cel Bun con Rumania ilustra que la articulación entre la libertad religiosa y la libertad sindical, puede entrar en conflicto cuando está en juego la autonomía de las confesiones religiosas. Frente a este conflicto, la CEDH ha optado por aplicar la doctrina del margen de apreciación nacional, al no existir un modelo único que regule las relaciones entre las Iglesias y los Estados, manifestando la voluntad de garantizar el derecho a la libertad religiosa.

De esta forma, la decisión del caso Sindicatul Pãstorul cel Bun adoptada por la Gran Sala de la $\mathrm{CEDH}$, el 9 de julio de 2013, constituye en este caso concreto, una victoria para la libertad religiosa sobre la libertad sindical, pero no se puede concluir que esta solución podrá satisfacer a todos los tipos de relaciones entre los Estados y las comunidades religiosas que existen en Europa.

Recibido: 20 de octubre 2013

Aceptado: 28 de febrero 2014

26 SOLAR, José Ignacio. "Pluralismo, democracia y libertad religiosa: consideraciones (críticas) sobre la jurisprudencia del Tribunal Europeo de Derechos Humanos". Cuadernos electrónicos de filosofía del derecho, No.15, 2007, pp. 3-4. 
